\title{
Practice and issue of energy policies to achieve greenhouse gas emission reduction targets in European countries
}

\author{
Jiyeon Kim*, Guk-Hyun Moon, Jong-Sam Lim \\ KEPCO Economy \& Management Research Institute, \#55 Jeollyeok-ro, Naju-si, Jeollanam-do, 520-350, Republic of Korea
}

\begin{abstract}
As the European leaders have pledged to reduce greenhouse gas emissions domestically by $40 \%$, the Member States of the European Union have implemented and promoted various energy policies to meet such target. It is important to investigate the feasibility of these energy policies and understand relevant issues because that will play an important role to realize a sustainable and cost-effective energy system for Europe. In this regard, this paper aims to analyze EU's major energy policies-namely, increasing the renewable energy contribution and improving the energy efficiency-designed to support the greenhouse gas emission reductions. The recently established energy polices of two major states-Sweden and Poland-are specifically addressed and compared that the government currently considers. In addition, this paper examines the advantages and disadvantages of these energy policies, and presents an improvement with a focus on their implications for developing countries. Finally, this paper suggests the direction of the energy policy mix for European countries based on examples of the technology transfer programs on inter-nations and the green climates fund.
\end{abstract}

Keywords: Energy efficiency, European energy policy, greenhouse gas emission target, renewable energy

\section{Introduction}

Significant progress has been made towards the attainment of the EU targets for greenhouse gas emission reduction by the utilizations of renewable energy and energy efficiency based on '2030 climate framework' identified in March 2014. In addition, the European Union have made an agreement with the 'Broad climate change pact' which constraining the greenhouse gas emitted by the whole EU to reduce by at least $40 \%$ by 2030 compared to 1990 in the October 2014. It reveals important messages because duty for greenhouse gas is generally given to only developed countries so far-e.g. UNFCCC COP18 in Doha, 2012. However, this ambitious EU Climate Target ensured all 28 EU Member States make significant emission reductions efforts through to 2030, compared to only 5 states before the deal, thereby creating a more level playing field for business [1].

In order to reliably achieve the greenhouse gas emission target, two additional $27 \%$ sub-targets were introduced and agreed-for renewable energy market share and increase in energy efficiency improvement. The former would be binding only on the EU as a whole. The latter would be optional, although its target level could be raised to $30 \%$ by a review in 2020 [2].

An EU target of at least $27 \%$ is set for the average ratio of renewable energy consumed in the EU in 2030. This target will be set to EU standard level, although several countries such as United Kingdom set their own national standard target. This goal could be satisfied through each country's renewable contributions directed by the need to deliver collectively the EU's renewable target. Besides, it would not obstruct Member States from setting their own more ambitious national-level objectives and supporting them, as well as incorporating their degree of integration in internal energy markets [3].

\footnotetext{
* Manuscript received May 5, 2013; revised September 15, 2015.

Corresponding author. Tel.: +82-61-345-3626; E-mail address: opensnow@kepco.co.kr.

doi: $10.12720 /$ sgce. $4.4 .355-360$
} 
One increasing challenges faced in terms of reducing greenhouse gas and increasing renewable energy contribution as well as energy efficiency is reaching the unified targets by all EU Member States. The business environments and financial conditions are different across Member States, thus their capabilities to adhere to the established targets are not same.

Meanwhile, German Chancellor Angela Merkel posted a positive not in late 2014 by mentioning that climate agreement on October 2014 has made the EU capable of being an important player on the international stage. It is also noted that the binding target of at least $27 \%$ renewable was particularly important to Germany and that those Member States, and that allowing Member States to setting more ambitious goals under this agreement is a welcoming idea. On the other hand, some less developed states such as Eastern-European countries including Poland, Czech Republic, Bulgaria, Romania, Slovakia and Hungary, have opposed the tough target because they have a high degree of dependence on coal, which effuse a lot of greenhouse gases, and tough climate goal should be barrier of economic growth. They said the emission reduction targets "must be set realistically" and the ambitious EU Climate Target is "just a whim of rich European countries." [4]

In this regard, this paper examines and analyzes EU's major energy policies designed to support the greenhouse gas emission reductions. Section 2 describes established energy polices of Sweden and Poland that the government currently considers. Section 3 investigates how these energy polices could be facilitated with taking account into their implications for developing countries, and finally Section 4 concludes this paper.

\section{Comparison of Generation Mix and Energy Policy for Reduction of Greenhouse Gas Emission Development in Europe}

\subsection{Sweden}

The reduction of greenhouse gas emissions has been a major recent source of concern for the energy industry in Sweden, which could result in climate changes and environmental problems [5]. Given that mitigations of greenhouse effects have been high on the agenda of the recent Swedish Government, the greenhouse gas emissions have been proactively handled by government legislative and regulatory policies. In turn, it is noted [6] that of Sweden has been achieved $12 \%$ of the reduction rate of greenhouse gas emissions, which among the highest in the EU from 1990 to 2008. In this sub-section, the detailed descriptions of energy polices for reducing greenhouse gas emissions driven by Swedish government are introduced and analyzed.

A number of environmental policies by the Swedish Government have been developed over many years based on ambitious objectives which include reduced climate impact raised by the greenhouse gas emissions [7]. One of the major strategies for reduction of the greenhouse gas suggested by the Swedish Government is to improve the energy efficiency with the Primary Energy Efficiency (PEE) program in energy intensive industries [8]. The PEE program aims to contribute to enhance the overall energy efficiency of the primary energy sector and consequently reducing greenhouse gas emissions.

In addition, another energy efficiency program-Improving Energy Efficiency Act (2004:1196) — came into force on 1 January 2005 in Sweden, intended to enhance the overall energy efficiency of energy intensive industries. The tax on industrial related electricity uses was increased from 0 to $0.005 \mathrm{Krona} / \mathrm{kWh}$ on 1 July 2004 to follow the order of the EU's Energy Tax Directive.

Energy-intensive companies in the manufacturing industry of Sweden would be provided the opportunity of being granted tax exemptions on the electricity energy consumptions, if companies' energy efficiency can be operated appropriately. In addition, the Swedish Government introduced a new program (Swedish abbreviation: PFE) of improving energy efficiency in energy-intensive companies with reducing their taxation. The PFE program is completely open to energy-intensive manufacturing companies in Sweden that can satisfy energy efficiency criteria and the participation in this program is voluntary.

In Sweden, the general program period for participating companies is set to 5 years. It needs to be noted that during the first two years of the program period, manufacturing companies should introduce 
and acquire a certification for a standardized energy management system. Consequently, during the remaining three years of the program, an energy review would be implemented to make a list of measures to improve their energy efficiency. Because the PFE program concentrates on the electricity-efficiency, the priority is considered based on recorded measures of the efficiency of electricity. Thus, if a manufacturing company in Sweden has participated in the PFE for two years, it would be required to submit an energy review report which consists of the energy management system and the list of measures. It is estimated that approximately 100 companies have participated in the PFE program during the 20052009 in Sweden.

An enhanced energy management system is presented in [9] to make it easier for a company to check its energy use and ensure the precise energy consumption monitoring. By incorporating the enhanced energy management system with improved operating and maintenance procedures and purchasing procedures, the manufacturing companies may decrease their energy consumption and, thereby, could reduce their electrical energy costs and relieve negative environmental impact. The Swedish standard for energy management system, SS 627750 had been widely used since 2003. This SS 627750 standard was replaced in 2009 by the European standard EN 16001 and an international standard (ISO) for energy management system is introduced in 2011. The manufacturing companies can introduce these energy management systems without participation of any types of the energy efficiency program.

Usually, the integration of renewable energy into the power system is being driven by the government policy. Such legislation may be extremely difficult to pass in many countries owing to various raised problems such as, under-estimated incentives, perceived inequities in the application, and overestimated blueprints. However, in Sweden, renewable energy is penetrated into the conventional power grid successfully based on the proactive government energy policies [9]. The Swedish Government outlined present energy policy in 1997. In addition, the Swedish Government promoted clean and sustainable energy use and a cheap energy supply that could realize an ecologically sustainable society. The green electricity certification was introduced in 2003 to promote use of renewable energy. In addition, the Swedish Energy Agency was set up to monitor renewable energy developments. Nowadays, renewable energy ratio in Sweden is $48 \%$ that is the highest in EU countries. Fig. 1 shows the framework for reducing greenhouse gas emissions by Swedish Government.

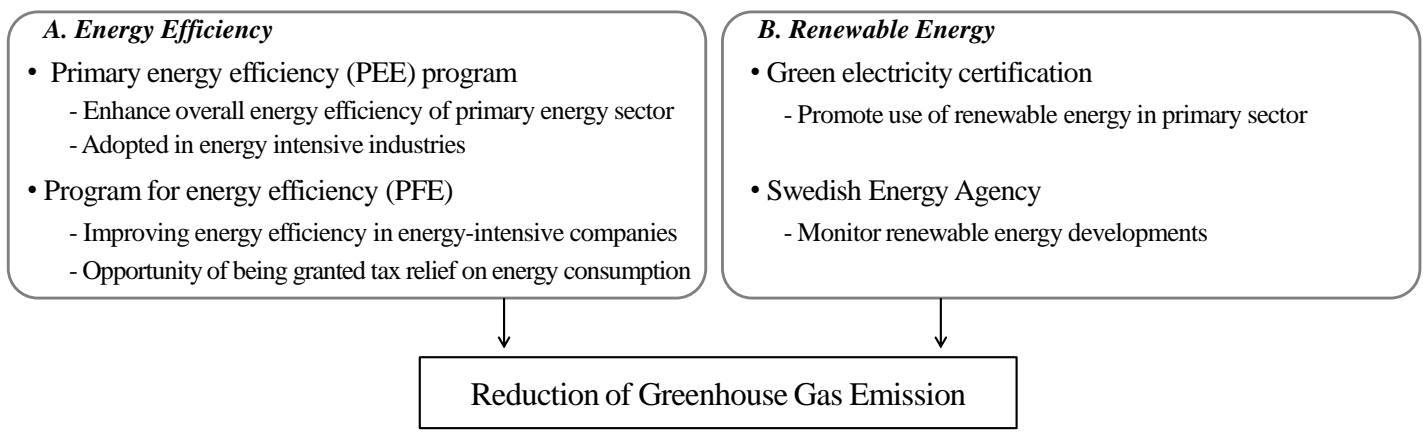

Fig. 1. Framework for reducing greenhouse gas emissions by Swedish government

\subsection{Poland}

Poland is one of the lower economic status countries in the European Union, with a GDP per capita of US\$13,653 in 2014. [10] Poland is Europe's second largest producer of coal and has a carbon-intensive economy due to its reliance on coal for more than $50 \%$ of its total energy demands [11]. The country generates more than $80 \%$ of the electrical power in the country from coal. Poland has maintained these practices for decades, because mining creates more than 100,000 jobs and makes great economy profit in concerned parts. Additionally, the transition to a low-emission economy by introducing alternative energy sources would require significant costs. For these reasons, Poland has opposed the pace of the ambitious EU Climate Targets, because this goal is too fast for Eastern European countries making efforts to 
promote their economic growth and restructure old industries [12].

Table 1. Polish electricity generation by sources

\begin{tabular}{|c|c|c|}
\hline $\begin{array}{c}\text { Sources of electricity power } \\
\text { generation }\end{array}$ & 2012 & $2030 *$ \\
\hline Black Coal & $53 \%$ & $37 \%$ \\
\hline Brown Coal & $32 \%$ & $23 \%$ \\
\hline Nuclear & - & $12 \%$ \\
\hline Liquid Natural Gas & $3 \%$ & $8 \%$ \\
\hline Renewable & $10 \%$ & $19 \%$ \\
\hline Other & $2 \%$ & $1 \%$ \\
\hline
\end{tabular}

The countries that disapprove of the EU Climate target, including Poland, the Czech Republic, Bulgaria, Romania, Slovakia, and Hungary, are certain that the target has a high possibility of raising their energy prices and negatively affecting their developing industries at a time when they are still resolving economic crises. This means they have no choice but to focus on producing energy using minimum costs. On the other hand, the ambitious new EU Target would mean additional costs for their economy and higher energy prices for consumers, because the reduction of GHG emissions involves highly advanced technology and systems that require great technology development costs.

Poland would be faced with considerable pressure to change its domestic energy mix and high costs for the transformation process if the EU's 2030 roadmaps were implemented. In principle, Poland agrees with and supports the EU climate policy, supporting the EU's efforts regarding GHG emissions reduction, renewable energy dissemination, and energy efficiency improvements. However, Poland opposes the measures to achieve the ambitious EU Climate targets in view of equality considering the different economic statuses of the EU members and contends that the target should be realistic [13].

Actually, the Polish government has not had a consistent energy policy for the transition to a lowemission economy so far, because their financial status has been low in Europe, so they should focus on their developing industries using their considerable coal resources regardless of greenhouse gas emissions.

Energy Policy of Poland until 2030 prepared by the Ministry of Economy and adopted by the government in 2009 is now being revised, including the contents about diversifying the energy mix towards nuclear power, gas, and renewable energy. Additionally, the National Programme for the Development of a Low-Emission Economy that focuses on energy efficiency and low-carbon technology that has been prepared since 2011 is to be completed [14].

Poland has just started to establish a policy related to renewable energy and reducing carbon gas, such as the reduction of greenhouse gas emissions. Poland has tried to build systems for producing renewable energy and environmentally friendly technologies. For example, Poland has reduced carbon gas emissions by 30 percent compared with levels in 1988, while expanding its economy by 130 percent. The use of energy by industries has decreased by 7 percent per year since the early 1990s, compared with the EU's average of 2.2 percent per year. This is partly the result of the closing of post-communist heavy industries, while new, cleaner sectors, such as electronics, have emerged [15], [16].

According to governmental analyses, these measures could mean increases in annual energy production costs by US\$2.4-3.6 billion, increases in energy prices of $60 \%$, and increases in monthly household expenditure on energy by $14-18 \%$, along with a decrease in GDP by $7.5 \%$, according to the Polish news agency PAP, quoting the country's minister in charge of restructuring the industry [17].

There are differences in the speed in enforcing policies related to climate change between Sweden and Poland. Sweden's policy has been established as a well-organized system, such as PEE, but Poland has just started to form and announce an energy policy, and they have a low capacity for the economic analysis of energy policies. According to IEA, restructuring Poland into a low-emission economy would require about 200 billion euros, which is almost 1.3\% of the annual GDP in Poland [18]. 
That is why Poland is assured that the EU climate framework should be changed to obtain a more developed status and take on a higher share of the economic costs. In this energy environment, increasing renewable energy, such as green energy, large wind farms, and solar panels, requires significant costs and time due to the necessity of technical development and new generating station construction [19].

Poland criticized the EU climate framework drafts presented in January 2008 for their failure to efficiently consider the principles of flexibility, cost-effectiveness, and fairness, the observance of which are critical due to the diversity of the EU states and their differences in energy mix [20], [21].

\section{Suggestion of Direction of Energy Policy Mix for Promoting Private Investigator Participations}

In this study, we verified that Eastern-Europe countries which have energy mix highly rely on coal and low GDP have barrier to follow the ambitious EU Climate Target. Connection between finance part for Member state's energy sector investments and the implementation of the energy plans of developing countries would be significant issue. EU already found out this and they have tried to establish climate fund for support developing countries in renewable energy sectors and transition to low-carbon economy, such as technology development for the reduction of the greenhouse gas emission [22].

However, EU is suffering from a decrease in investment. Gross capital investment has fallen by $21 \%$ since 2007. At the same time, the EU has enormous investment needs, particularly in energy infrastructure. However, Regulatory uncertainty is an important barrier to investment, encouraging investors to hesitate. That's why EU needs a regulatory framework to promote investment demand from sectors with large investment needs, including the energy sector. Furthermore, investment from private sector should be required to get over limit of the public investment, also it contributes to the revitalization of new investment [23].

Especially, the Green Climates Fund (GCF) could be an attractive example for supporting greenhouse gas reduction in developing countries. Compared with the existing climates funds, the GCF has a discriminated characteristic with respect to the promoting the private investigator participations. The GCF efficiently provides a prominent mechanism with a connection of the public and private financial resources. In addition, in order to minimize the investment risks of the private investment, the GCF establishes a Private Sector Facility (PSF). The PSF is affiliated with the GCF and conducts important roles in the early years funding. Moreover, this PSF could be more efficient for supporting developing countries, because such system could stimulate private investigator participations and facilitate financial procurements raised by regional financial institutions. [23], [24]

\section{Conclusions}

The results of this paper could be the basis for critical revision of energy policies of the European Union, especially for the renewable energy contribution and improving the energy efficiency. EU and its Member States must carefully consider their right role as well as the balance among 1) different policies, 2) the economic status, and 3) the member states.

The transition to a low-emissions and organization of energy efficiency system is long-term and complicated, requiring various discussions to deal with different policy barriers. EU faced the additional challenge of guiding this transition, while balancing burden-sharing between Member States and EU capabilities. Thus we need to consider the ambitious EU Climate Target on three dimensions.

First of all, we should think about the balance between Member State and EU competence, because EU shares an economic and geopolitical destiny, Member States' individual and collective energy goals cannot be accomplished in isolation. [21]

Secondly, considering various Member State's different economy status in achieving the new target is needed. Another important issue will be the linkage between financing for Member state's energy sector investments and the effective implementation of the national energy plans. The 2030 Climate Energy Framework presents a timely opportunity for investing in the low carbon transformation of the European energy sector. To stimulate this investment, the Framework must deliver a clear vision of EU's right goal 
where the EU would go.

Third, Promoting participation of private sector to the investment related to reduction GHG emissions should be considered. Developing countries have poor surroundings in Climate adaptation and mitigation comparing developed countries in EU. Therefore, it is required to enhance developing countries' access to high quality research and information on climate change response .[23] Although, the de-carbonization of the EU economy won't happen without financial support, EU still don't have a clear policy and wellorganized system to meet its commitments on climate financing for developing countries. That's why we should encourage operate climate fund like Global Climate Fund (GCF). GCF increases the leverage of private investments thorough PSF. It reduces investment risk and supply high quality researches, monitoring and analysis related to the investment.

\section{References}

[1] EU agrees 'historic' deal to tackle climate change. DECC Press Release; October 2014.

[2] Neslen A. The Guardian. (October 2014). EU leaders agree to cut greenhouse gas emissions by $40 \%$ by 2030 . [Online]. Available: http://www.theguardian.com/world/2014/oct/24/eu-leaders-agree-to-cut-greenhouse-gas-emissions-by-40-by-2030

[3] Environmental Protection Agency. (April 2015). Greener living. [Online]. Available: http://www2.epa.gov/learn-issues/learnabout-greener-living

[4] Coal-Rich Countries May Block New EU Climate Deal. [Online]. Available: http://www.manufacturing.net/news/2014/10/coal-rich-countries-may-block-new-eu-climate-deal

[5] Adahl M. The reduction in greenhouse gas emissions. Fores Policy Paper, 2011; 4(1):1-52.

[6] Sweden Sverige. (March 2014). Sweden's Environmental Policy. [Online]. Available: https://sweden.se/nature/environmentalpolicy

[7] Nordic Energy Research. Standards for Measuring Energy Use in Buildings with District Heating. [Online]. Available: http://www.nordicenergy.org/project/measuring-energy-efficiency-in-buildings

[8] Swedish Ministry of the Environment. Sweden's First Biennial Report under the UNFCCC, 2014.

[9] European Renewable Energy Council, A Sustainable Energy Outlook for Sweden - The Advanced Energy Revolution, 2011.

[10] OECD, OECD Economic Surveys Poland, 2014.

[11] The Epoch Times. (October 2014). Coal-Reliant Poland Plans to Block EU Greenhouse Gas Reduction. [Online]. Available: http://www.theepochtimes.com/n3/1036767-coal-reliant-poland-plans-to-block-eu-greenhouse-gas-reduction

[12] [Online]. Available: http://www.rtcc.org/2014/10/29/poland-won-eu-2030-deal-does-the-climate lose/\#sthash.iAD6VQ3R.dpuf

[13] OECD, Climate Change policies in Poland, 2012.

[14] Polish Ministry of Economy, Energy Policy of Poland Until 2030, 2009.

[15] Carbon Market Watch, Analysis of Europe's 2030 Climate Ambition, 2014.

[16] OECD, Environmental Performance Reviews Poland, 2015.

[17] Polish Ministry of Environment, Environment Policy in Poland Climate and Energy Policy ,2013.

[18] Anna P. Assessment of climate change policies in the context of the European semester. Country Report: Poland, Ecologic Institute Paper, 2013.

[19] McKinsey\&Company, Assessment of Greenhouse Gas Emissions Abatement Potential in Poland by 2030, 2011.

[20] Evans S. (October 2014). Carbon Brief. The EU's 2030 Climate Target. [Online]. Available: http://www.carbonbrief.org/blog/2014/10/q-and-a-the-eus-2030-climate-targets/

[21] Thomas Spencer, IDDRI: What is Needed in the EU's 2030 climate and Energy, December 2014.

[22] Accenture. The Green Investment Report ways and Means to Unlock Private Finance for Green Growth, 2013.

[23] Youngs R. The EU's global climate and energy policies. FRIDE Working Paper, 2013.

[24] Climate Policy Initiative, Operationalizing the Private Sector Facility of te Green Climate Fund: Addressing Investor Risk, 2014. 